\title{
DEVELOPMENT OF ALOE VERA SQUASH USING DIFFERENT FRUIT JUICES
}

\author{
Samuel Jaddu ${ }^{1}$, Aparna Kuna ${ }^{2}$, Shaik Zeenath ${ }^{3}$, Divya K ${ }^{4}$, Jyothsna L ${ }^{5}$, Vamsi Vihar ${ }^{6}$ \\ ${ }^{1,3,4,5,6}$ Senior Research Fellow, College of Food Science \& Technology, Bapatla, Andhra Pradesh, India \\ ${ }^{2}$ Scientist QC Lab, Professor JayaShankar Telangana Agricultural University
}

\begin{abstract}
Aloe is known as 'Ghee-kanwar' or 'Ghi-kuvar' in hindi and has been in use since ages as folk medicine. Brihans natural products from Tamil nadu are the first company, supplying organic aloe juice to European countries. Major areas of aloe production are Alwar in Rajasthan, Satnapalli in A.P, Rapipla in Gujarat etc. Total production of aloe is estimated to be about 1,00,000 tonnes per year in India. The price of fresh aloe leaves ranges from Rs.40 to 55 per Kg. The process of making Aloe Vera Squash was standardized by adding different fruit juices like $L, P, G, O$ and their compositions nearly around $25 \%$ along with $75 \%$ raw aloe juice \& its nutritional and physico-chemical characteristics were assessed. The recovery rate of Aloe Vera Juice from Aloe Vera Leaf was nearly around $300 \mathrm{ml} \mathrm{per} 1 \mathrm{~kg}$ of Aloe Vera. It contained substantial amount of vit c $12.5 \mathrm{mg}$, CHO $150 \mathrm{mg}$, Ca $28 \mathrm{mg} \& 125 \mathrm{kcal}$ energy value. The TSS of Aloe Vera Squash was $43.8^{\circ}$ brix. Sensory analysis showed that the Aloe Vera Squash which is mixed L, G, O resulted in most acceptable when compared to Aloe Vera Squash prepared from P. And also, this blending of different fruit juices improved the color, taste, flavor \& overall acceptability of Aloe Vera Squash
\end{abstract}

Keywords: Aloe Vera, Aloe Vera Squash

\section{INTRODUCTION}

Aloe vera was mainly used for its therapeutic purposes for centuries ago. The applicability of aloe for various reasons was quite evident in countries like Egypt, India, Greece, China and Rome.

Aloe was originated from tropical Africa and cultivated in hot climatic continent regions. It will survive temperatures higher still, and can withstand even severe drought. Aloe vera belongs to the lily family. Out of all species, merely one would be the real aloe. Mere authentic AV offers many potential physiological benefits. AVG was found best treatment for diabetics. As scientific research was enhanced in chemical, medical \& physical field, it was more useful food ingredient as a functional component. Aloe vera has been treated as one modern miracle medicine. Aloe vera and its products are most popular for making nutraceutical and functional beverages. The aloe vera industry is rising day by day manufacturing variety of products for multipurpose use.

AV helps for strengthening immune system \& it cleans the toxins that are built up in our body. AV is naturally blood purifier and rich in $\mathrm{Ca} \&$ helps in absorption of $\mathrm{Ca} \&$ it improves bone health helps in development of cartilage strengthens joint. Regular consumption of AV helps to lower blood glucose level \& it helps faster healing of diabetic wounds. AV can also be used to treat constipation, diarrhoae, ulaerative cotilis \& irritable bowel syndrom.

Worldwide, it has enomorous attraction to the consumers for preparation of health drinks as a functional beverages and attaining growth in food industry. Now a days, Indian food industry emphasizing the functional ingredients like aloe vera for making the health based drinks and beverages like tea and etc. By the way, aloe industry drastically requires expansion for its regulatory and quality aspects and to ensure safe food product. The present investigation focus on the following objectives that are to reduce bitterness of Aloe Vera juice and improve the overall acceptability of Aloe Vera Squash and increase the nutritive value of Aloe Vera Squash by blending different fruit juices like lemon, grape, orange and pomegranate.

\section{MATERIALS AND METHODS}

In the present chapter, the materials and the methodology adopted for preparation of blended aloe vera squash are discussed.

\subsection{Procurement of Raw Materials:}

The raw materials used in the preparation of blended aloe vera squash are as follows

Fresh, well graded, highly colored of good commercial quality aloe vera were collected from the local places in Bapatla for experimental purpose. Commercial grade, white crystalline sugar was procured from the local market for the preparation of sugar syrup to be used for adjusting the brix of blended aloe vera squash. Processed and odour free water was used for the preparation of sugar syrup. Citric acid, sodium benzoate were used as a preservative for preserving the blended aloe vera squash.

\subsection{Selection of Aloe Vera:}

All aloe vera are not suitable for squash preparation due to low quality of obtained juice from various varieties and for some varieties extraction might be difficult. Hence the selection of particular variety of aloe vera is very crucial. Over ripen and green $\mathrm{AV}$, if adversely affect the quality of juice. For better results, fully ripen aloe vera would be more suitable. 


\subsection{Process Obtaining Juice:}

First aloe vera leaf has to be filleted there after outer layer of green portion and yellow colour exudates aloin to be removed. The filleted leaf is cut into slices of uniform sizes and thickness of $10 \mathrm{~mm}$. Initially the obtained gel was viscous, enzymatic reaction makes the gel as free flowing liquid. Blanching was performed at $92^{\circ} \mathrm{c}$ for 3-5 minutes. The main objective of this operation is not merely inactivate the deteriorative enzymes, microbes and to soften the tissue and reduce the viscous nature of AVL. The need for standardisation for AV juice manufacturers is to regulate the amount of aloin present in the end product for AV juice.

\subsection{Preparation of Sugar Syrup:}

Sugar syrup of $50^{\circ}$ brix was prepared by mixing sugar and water in the ratio of $1: 1$ and citric acid at the rate of 10 $\mathrm{gm} /$ lit was added then the mixture was heated at temperature of $80^{\circ} \mathrm{c}$ to dissolve the solutes and content was filtered through muslin cloth. The syrup was then cooled prior to mixing with juice.

Flow chart for blended aloe vera squash

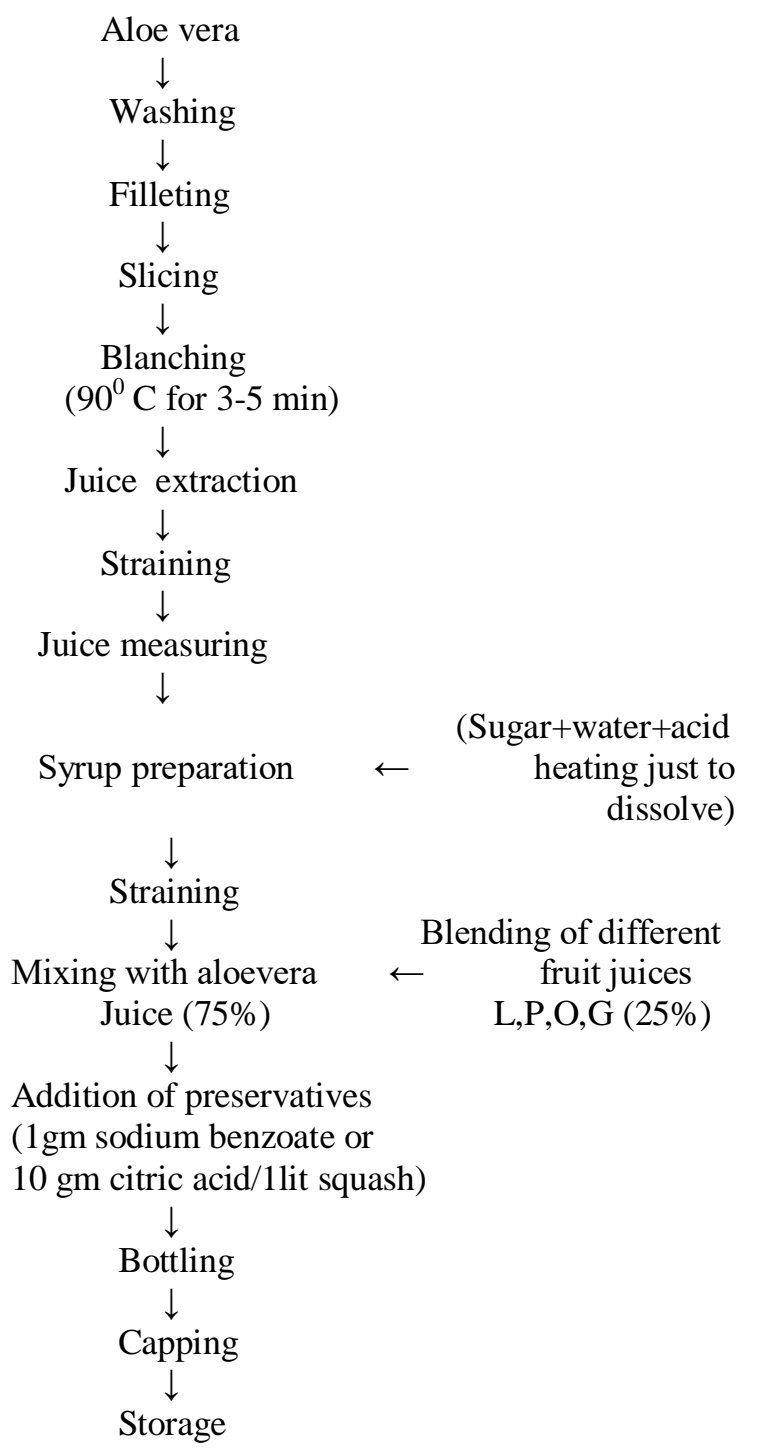

Codes for Sample formulations:

\begin{tabular}{cc}
\hline Code & Sample formulations (juice) \\
\hline $\mathrm{S}_{1}$ & $75 \%$ aloe vera $+25 \%$ lemon \\
\hline $\mathrm{S}_{2}$ & $75 \%$ aloe vera $+25 \%$ orange \\
\hline $\mathrm{S}_{3}$ & $75 \%$ aloe vera $+25 \%$ grape \\
\hline $\mathrm{S}_{4}$ & $75 \%$ aloe vera $+25 \%$ pomegranate \\
\hline
\end{tabular}

\section{CHEMICAL ANALYSIS}

Method of preparing squash had an influence on the quality \& quantity of the product. so as to analyse certain parameters in the experiment has been conducted.

\subsection{Estimation of Total Soluble Solids:}

Total soluble solids (TSS) are estimated by using hand refractometer. TSS of a given sample of fruit juice represents the various chemical substances present in the soluble form. It indicates a measure of sugars present in the sample. The instrument works on the principle of refractive index of the sample and gives the RI as ${ }^{0}$ brix. The amount of TSS present in the juice of a fruit is also considered to be a reliable index in judging of its maturity.

\subsection{Estimation of Carbohydrate:}

Sugars are estimated by following Nelson- Somoyogi method as reported by Nelson (1988).In this method first the total sugars and the reducing sugars are extracted by taking the known volume of the sample. To this extract alkaline copper reagent and arseno molybdate reagent was added and the color intensity is measured at 520nm spectrometrically. Simultaneously run the standard graph carbohydrate content of the sample was estimated.

\subsection{Energy Value:}

Energy value is estimated by using bomb calorimeter, in which the difference in initial and final temperatures upon calculation gives the energy value of the product.

\subsection{Estimation of Minerals:}

Minerals are estimated by using atomic absorption spectrophotometer. In this method the samples are initially digested with mixture of acids. The digested mixture was made upto the known volume and used for estimation. Sample was sprayed into the frame of an atomic absorption spectrophotometer and absorption of the calcium was measured at $422 \mathrm{~nm}$.

\subsection{Calcium:}

Calcium content is estimated by using calorimetric method, in which the sample was titrated against oxalic acid. Same as to blank. The difference in titre values gives $\mathrm{Ca}$ content. 


\section{RESULTS AND DISCUSSIONS}

The various samples of AVS that were prepared using different proportions of various Fruit juices were analysed. This chapter deals with the analysis of sample's data.

\subsection{Proximate Analysis}

The Proximate analysis was carried out for the various samples and the Values of $\mathrm{CHO}$, Vit C, Ca, TSS, energy were determined

\subsubsection{Carbohydrate}

The Carbohydrate content of samples was decreased from $S_{1}$ to $S_{4}$ which was probably due to the presence of sugars in fruit juice. The sample made of $\mathrm{S}_{1}$ had the highest $\mathrm{CHO}$ $(140 \mathrm{mg} / 100 \mathrm{ml})$, while the sample $\mathrm{S}_{4}$, containing only (62 $\mathrm{mg} / 100 \mathrm{ml})$.

\subsubsection{Total Soluble Solids}

The TSS content of samples was increased from $S_{1}$ to $S_{4}$ which was probably due to the presence of soluble solids. The sample made of $\mathrm{S}_{4}$ has the highest TSS $\left(62.8^{0}\right.$ brix $)$ and least containing of $\mathrm{S}_{1}\left(48.5^{0}\right.$ brix $)$

\subsubsection{Vitamin C}

The Vit C content of samples was decreased from $S_{1}$ to $S_{3}$ while $S_{4}$ had increased. The sample made of $S_{1}$ has highest Vit C (27.09 mg/100 ml) while least has $S_{3}(15.48 \mathrm{mg} / 100$ $\mathrm{ml})$.

\subsubsection{Energy}

The energy value of samples increased from $S_{1}$ to $S_{4}$. The sample made of $S_{4}$ has the highest value $(150 \mathrm{Kcal})$ while least has $\mathrm{S}_{1}(125 \mathrm{Kcal})$.

\subsubsection{Calcium}

The Calcium content of samples was decreased from $\mathrm{S}_{1}$ to $S_{4}$. The sample made of $S_{1}$ has the highest value $(47 \mathrm{mg} / 100 \mathrm{ml})$ while lowest has $\mathrm{S}_{4}(35 \mathrm{mg} / 100 \mathrm{ml})$.

\subsection{Sensory Evaluation}

The Sensory evaluation for all the five samples was made by a panel Containing 10 semi-skilled members. 9 point Hedonic scale was used to evaluate the sensory parameters of the samples. The different sensory parameters that were taken into consideration while evaluating the samples were Color, appearance, flavor, taste and overall acceptability.

\begin{tabular}{llll}
\hline Sample Color Appearance Taste Flavor $\begin{array}{c}\text { Overall } \\
\text { acceptability }\end{array}$ \\
\hline $\mathrm{C}$ & & \\
\hline $\mathrm{S}_{1}$ & \\
\hline $\mathrm{S}_{2}$ & \\
\hline $\mathrm{S}_{3}$ & \\
\hline $\mathrm{S}_{4}$ & \\
\hline
\end{tabular}

\subsubsection{Color and Appearance}

The color and appearance of samples $S_{1} \& S_{2}$ was compared with $S_{3} \& S_{4}$ showed significant difference. The samples of $S_{1} \& S_{2}$ had pale in color. The Samples $S_{3} \& S_{4}$ showed not much significant difference, they are in light pink in color.

\subsubsection{Flavor}

The flavor of samples varies from sample to sample because we were added different fruit juices with different proportions. But all the samples were exhibiting good flavor.

\subsubsection{Taste}

The taste of the samples from $S_{1}$ to $S_{3}$ were good and liked very much one was $S_{1}$ while not liked much was $S_{4}$ because in which pomegranate taste was dominated and not tasty.

The Overall acceptability of the samples from $S_{1}$ to $S_{3}$ was good due to High flavor and taste in them. The Sample $S_{1}$ was most acceptable and Sample $S_{4}$ was not much acceptable.

\section{Proximate Analysis of Developed Aloe Vera Squash}

\begin{tabular}{cccccc}
\hline Sample & $\mathrm{CHO}(\mathrm{mg} / 100 \mathrm{ml})$ & $\mathrm{TSS}^{\circ}$ brix & $\mathrm{Ca}(\mathrm{mg} / 100 \mathrm{ml})$ & $\mathrm{Vit}_{\mathrm{C}}(\mathrm{mg} / 100 \mathrm{ml})$ & Energy(Kcal) \\
\hline $\mathrm{C}$ & 53.63 & 43.8 & 28 & 10.69 & 105 \\
\hline $\mathrm{S}_{1}$ & 140.48 & 46.5 & 46 & 32.5 & 125 \\
\hline $\mathrm{S}_{2}$ & 97.79 & 48.5 & 42.0 & $\mathrm{I}$ & 136 \\
\hline $\mathrm{S}_{3}$ & 92 & 62.5 & 37.0 & 14.1 & 140 \\
\hline $\mathrm{S}_{4}$ & 62 & 52.5 & 34.0 & 145 \\
\hline
\end{tabular}




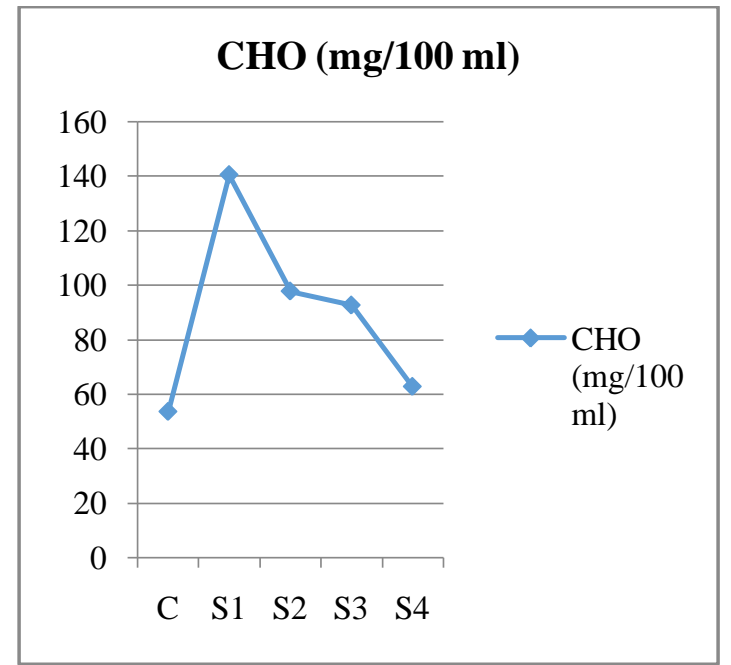

Fig.1: Analysis of $\mathrm{CHO}$

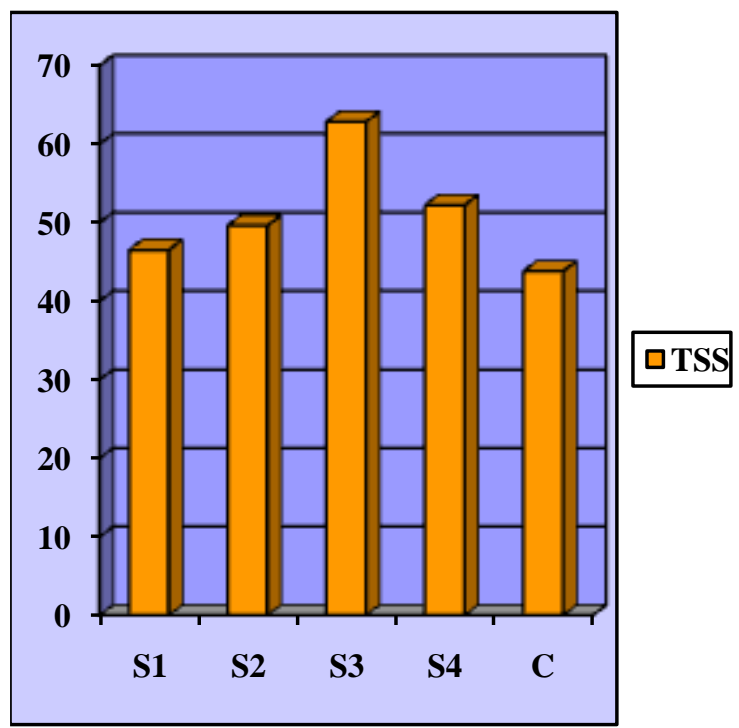

Sample formulations

Fig.2: Analysis of TSS

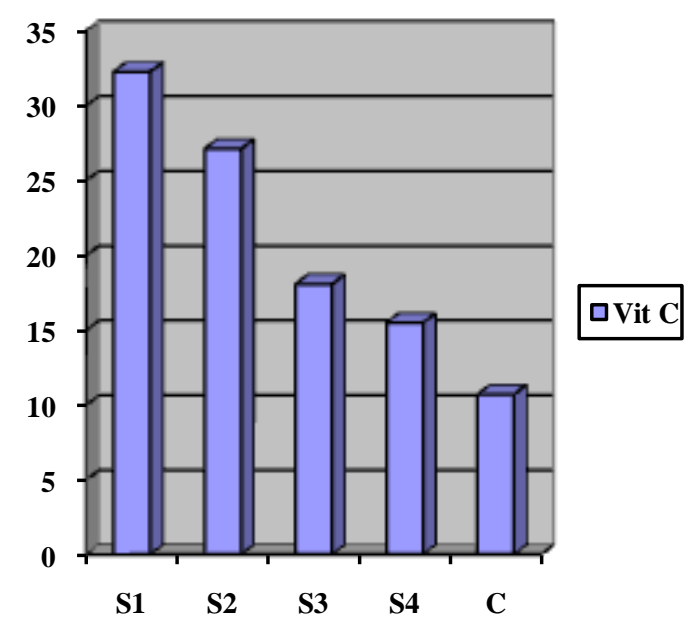

Sample formulations

Fig.3: Analysis of Vitamin C

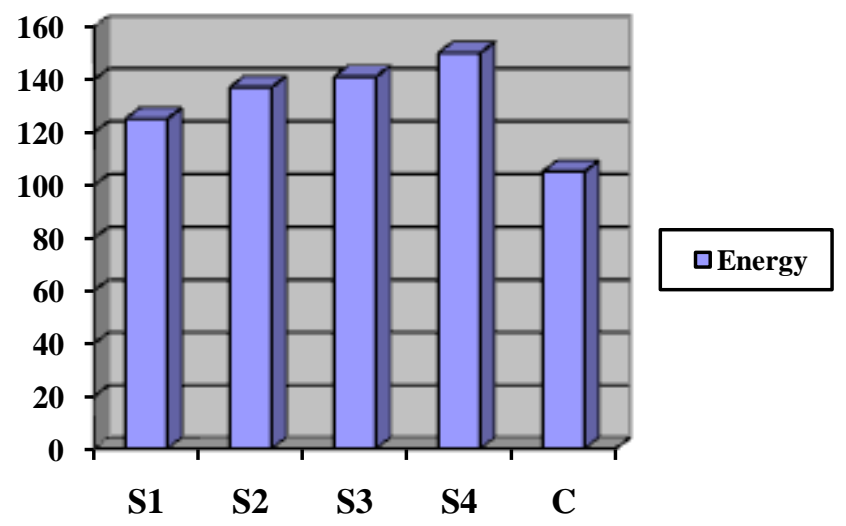

Sample formulations

Fig.4: Analysis of Energy

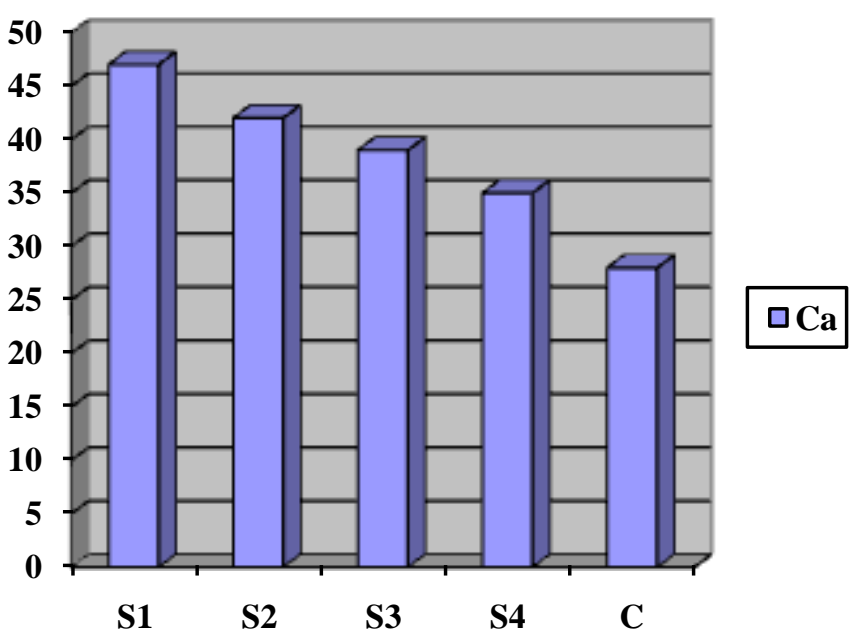

Sample formulations

Fig.5: Analysis of Calcium

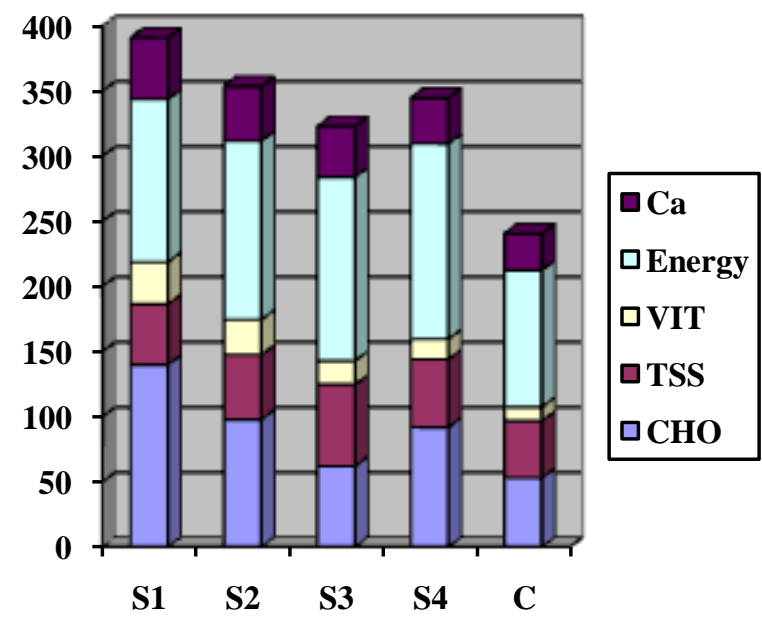

Sample formulations Fig.6: Analysis of AVS 


\section{SUMMARY AND CONCLUSIONS}

The processing of aloe vera in India is not at all popular in food processing sector inspite of having lot of potential health benefits in nutritional point of view. So, utilisation of aloe vera and the blending aloe vera with various fruit juices will lead to the product diversification.

Aloe vera squash was prepared with standard procedure. But it was not acceptable in consumers point of view because of its color and overall acceptability. Apart from that aloe vera taste was dominating which was disliked by most of the sensory panel members. The gummy or viscous nature of aloe vera gel or meat was coming when evaluating the sample. It was removed by the operation called as blanching for $5 \mathrm{~min}$ at $90{ }^{\circ} \mathrm{C}$. In order to improve the color, overall acceptability and masking the aloe vera flavour, the different fruit juices at $25 \%$ concentration are added to the $75 \%$ aloe vera juice. We were followed procedure as similar to standard squash preparation. The samples were analysed as following $\mathrm{S}_{1}, \mathrm{~S}_{2}, \mathrm{~S}_{3}$ and $\mathrm{S}_{4} \&$ Control. Sensory evaluations of the samples showed that the samples $S_{1}$ to $S_{3}$ had good acceptability in terms of color, flavor, appearance and overall acceptability. The sample $\mathrm{S}_{4}$ had an unacceptable taste and aroma. After considering the all sensory parameters it has been found that the sample $S_{1}$ was highly acceptable, $S_{2} \& S_{3}$ were also were acceptable.

\section{REFERENCES}

[1] Aloe Vera - A scientific approach: David,Rober. Vantage Press Inc, 1997.

[2] Bunyapraphatsara N, Yongchaiyudha S, Rungpitarangsi V, Chokechaijaroenporn O. Antidiabetic activity of Aloe Vera L. juice. II. Clinical trial in diabetes mellitus patients in combination with glibenclamide. Phytomed 1996; 3:245-48.

[3] Bruce W. Investigations of the antibacterial activity in the aloe. S Afr Med J 1967; 41:984.

[4] Blumenthal M, Busse WR, Goldberg A, et al, eds. Monographs: Therapeutic Guide to Herbal Medicines. Boston, MA: Integrative Medicine Communications, 1998, 80-81.

[5] Ajabnoor M. Effect of aloes on blood glucose levels in normal and alloxan diabetic mice. J Ethnopharmacol 1990;28:215-20.

[6] Syed TA, Ahmad SA, Holt AH, et al. Management of psoriasis with Aloe vera extract in a hydrophilic cream: A placebo-controlled double-blind study. Trop Med Int Health 1996; 1:505-9.

[7] Visuthikosol V, Choucheun B, et al. Effect of Aloe Vera to healing of burn wound: A clinical and histologic study. J Med Assoc Thai 1995; 78:403-9.

[8] Blitz J, Smith J, Gerard J. Aloe vera gel in peptic ulcer therapy: Preliminary report. J Am Osteopathic Assoc 1963; 62: 731-35.

[9] AV-USA book review: The health \& medicinal use of $\mathrm{AV}$. His contribution to the aloe literature is timely and will be welcomed by all who are working in the review by Jane Rubin AV-USA Feb 1998.

[10] Department of complementary medicine, school of PG medicine \& health sciences, university of Excter.

[11] AV:A systematic review of its clinical effectiveness.

[12] The health professional's guide to dietary supplements by shown M.Talbott, Kerry Hughes.

[13] Harding TBC (1979) Aloes of the world: a checklist, index and code. Excelsa 9:57-94

[14] Eshun K, He Q (2004) Aloe vera: a valuable ingredient for the food, pharmaceutical and cosmetic industries: a review. Crit Rev Food Sci Nutr 44:91-96

[15] Christaki EV, Florou-Paneri PC (2010) Aloe vera: a plant for many uses. J Food Agric Environ 8(2):245249

\section{BIOGRAPHIES}

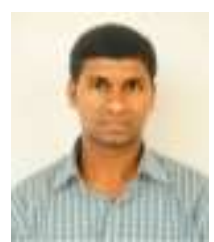

Er. Samuel Jaddu has worked as Assistant Professor (C) in School of Food Technology for 3 Years and 9 Months in JNTUK Kakinada.

Now presently working as SRF in College of Food Science \& Technology, Bapatla, AP.

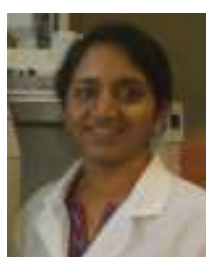

Aparna Kuna, Ph.D is working as Scientist (Foods \& Nutrition), Quality Control Laboratory, Professor Jayashankar Telangana State Agricultural University in Hyderabad, India since 2006. She is involved in teaching and research activities in areas of food analysis, human nutrition, food processing and food science. Her research centers around functional foods, nutraceuticals for Cardiovascular disorders and diabetes; value addition to underutilized foods and extrusion cooking. 